\title{
Intracellular targets of RGDS peptide in melanoma cells
}

\author{
Maria Simona Aguzzi1 ${ }^{1}$ Paola Fortugno², Claudia Giampietri³ ${ }^{3}$ Gianluca Ragone 4 , Maurizio C Capogrossi ${ }^{1}$ and \\ Antonio Facchiano*1
}

\begin{abstract}
Background: RGD-motif acts as a specific integrins-ligand and regulates a variety of cell-functions via extracellular action affecting cell-adhesion properties. However, increasing evidence identifies additional RGDS-functions at intracellular level. Previous reports show RGDS-internalization in endothelial cells, cardiomyocytes and lymphocytes, indicating intracellular targets such as caspase-8 and caspase-9, and suggest RGDS specific activity at cytoplasmic level. Given the role RGDS-peptides play in controlling proliferation and apoptosis in several cell types, investigating intracellular targets of RGDS in melanoma cells may un-reveal novel molecular targets and key pathways, potentially useful for a more effective approach to melanoma treatment.
\end{abstract}

Results: In the present study we show for the first time that RGDS-peptide is internalized in melanoma cells in a timedependent way and exerts strong anti-proliferative and pro-apoptotic effects independently from its extracellular antiadhesive action. RGES control-peptide did not show biological effects, as expected; nevertheless it is internalized, although with slower kinetics. Survivin, a known cell-cycle and survival-regulator is highly expressed in melanoma cells. Co-immunoprecipitation assays in cell lysates and overlay assays with the purified proteins showed that RGDS interacts with survivin, as well as with procaspase-3,-8 and -9. RGDS-peptide binding to survivin was found to be specific, at high affinity (Kd $27.5 \mu \mathrm{M})$ and located at the survivin C-terminus. RGDS-survivin interaction appeared to play a key role, since RGDS lost its anti-mitogenic effect in survivin-deprived cells with a specific siRNA.

Conclusions: RGDS inhibits melanoma growth with an adhesion-independent mechanism; it is internalized in melanoma cells and specifically interacts with survivin. The present data may indicate a novel role of RGDS-containing peptides physiologically released from the extracellular matrix and may suggest a possible novel anti-proliferation strategy in melanoma.

\section{Background}

RGD (Arg-Gly-Asp) motif is largely investigated as mediator of cell adhesion to extracellular matrix and to cells, via cell-surface receptors named integrins. These receptors belong to a large family of twenty-four heterodimeric members. Several integrins, including $\alpha_{\mathrm{v}} \beta_{3}, \alpha_{5} \beta_{1}, \alpha_{\mathrm{v}} \beta_{5}$, $\alpha_{\mathrm{v}} \beta_{6}$ and $\alpha_{\mathrm{II}} \beta_{3}$, recognize the RGD motif present in various ECM proteins such as fibronectin, vitronectin, laminin, fibrinogen, von Willebrand factor, osteopontin, thrombospondin, and collagen [1] as well as in disintegrins; others including $\alpha_{1} \beta_{1}, \alpha_{2} \beta_{1}, \alpha_{10} \beta_{1}$, and $\alpha_{11} \beta_{1}$, interact with the matrix in a RGD-independent manner [2-4].

\footnotetext{
* Correspondence: a.facchiano@idi.it

1 Laboratorio Patologia Vascolare, Istituto Dermopatico dell'Immacolata, IDIIRCCS, Roma, Italy

Full list of author information is available at the end of the article
}

Integrins activation triggers different signals regulating cell adhesion, migration, survival, apoptosis $[1,5,6]$ as well as processes such as angiogenesis, thrombosis and osteoporosis [7-9]. Further, integrins control the interaction of tumor cells with the surrounding environment, with a direct effect on cell proliferation, migration, metastatic dissemination, invasion, cell survival [10,11]. RGD motifcontaining peptides bind integrin receptors with high affinity and inhibit cell adhesion by competing the integrins/matrix interaction leading to anti-inflammatory, anti-coagulant and anti-metastatic effects, as well as antiangiogenic effects [12-15]. RGD peptides are also involved in tumor and endothelial cells-targeting via the $\alpha_{v} \beta_{3}$ receptors [16-19] as well as in noninvasive tumor imaging, targeting and radio-treatment [20]. 
RGD-containing peptides inhibit cell growth by inducing cells-detachment from extracellular matrix and adhesion-dependent apoptosis, named anoikis [21]. An additional mechanism, previously investigated by us and Others, involves RGD peptides cell-internalization, intracellular targeting and direct activation of caspase-3, caspase- 8 or caspase- 9 in lymphocytes, cardiomyocytes, endothelial cells and chondrocytes, leading to apoptosis most-likely via an integrin-independent mechanism [3,22-24]. These findings suggest that RGD motif, in addition to targets exposed onto the external surface of cell membrane, recognizes intracellular targets (namely caspases), leading to procaspase auto-processing and activation.

Survivin is a member of the Inhibitor of Apoptosis Protein (IAPs) family; it is involved in multiple functions, including control of cell division, apoptosis and cellular response to stress [25]. Survivin is selectively expressed during development and in proliferating cells; it increases during G1 cell-phase and reaches a peak-level at G2-M phase. Survivin expression level is very low or undetectable in most differentiated tissues, in the absence of stress conditions, while normally it is expressed in thymus, basal colonic epithelium, endothelial cells and neural stem cells during angiogenesis [25]. Survivin plays a critical role in cancer biology; it is selectively expressed in transformed cells and in most cancers as breast, lung, pancreatic and colon carcinomas, haematological tumors, sarcomas and neuroblastoma. Further, it is expressed in melanocytic nevi, melanoma metastatic lesions and invasive melanomas, but not in normal melanocytes [26]. Survivin is a survival factor for cancer cells and its over-expression correlates with unfavorable prognosis, high recurrence risk, metastasis, high resistance to both chemo- and radio-therapy [27]. Due to its role in cancer resistance to apoptotic stimuli, survivin has been proposed as a potential target for anticancer therapies based on antisense oligonucleotides, small interfering RNAs, ribozymes and dominant negative mutants [2831].

In the present study we investigated for the first time intracellular targets of RGDS peptide in human metastatic melanoma cells and identified survivin as a novel direct target of RGDS molecule.

\section{Results}

\section{RGDS effect on SK-MEL-110 proliferation and apoptosis}

As we and others previously demonstrated [2-4], cell adhesion to collagen-IV is RGD-independent. We further confirmed such observation on SK-MEL-110 cells (unpublished data). We therefore investigated cells seeded onto collagen IV-coated plastic throughout the whole study, in order to investigate RGDS-effects inde- pendently of its anti-adhesive action. Melanoma cells proliferation induced by FGF-2 was significantly reduced in the presence of RGDS (Figure 1A top) (46 $\pm 16 \%$ inhibition, $\mathrm{p}<0.005)$ at $500 \mu \mathrm{g} / \mathrm{ml}$, indicating that, despite the presence of the strong survival factor FGF-2, RGDS exerts a potent anti-proliferative effect on SK-MEL-110 cells, independently of its anti-adhesive properties. Control peptide RGES had no anti-proliferative effect, as expected. The effect is shown in one representative field (Figure 1A bottom).

RGDS-treated cells were stained with propidium iodide (PI) and cell cycle was investigated. RGDS-treatment (48 $\mathrm{h}, 500 \mu \mathrm{g} / \mathrm{ml}$ ) increased the percentage of cells in sub-G1phase from 3\% (with FGF-2 alone) to $13.2 \%$ (with FGF-2 and RGDS) (Figure 1B top and bottom), indicating that RGDS may induce apoptosis in melanoma cells, in the presence of FGF-2. RGDS-treatment also increased number of cells in G1-phase, vs control (77\% vs 67\%), and markedly reduced cell-number in S (3.5\% vs $8.7 \%)$ and in G2-phase (9\% vs 16\%) (Additional file 1).

\section{RGDS cell internalization}

We then investigated whether RGDS is internalized into SK-MEL-110, by exploiting different experimental approaches. RGDS internalization in live cells was quantified by FACS analysis. The biotinylated peptide entered into melanoma cells in a time-dependent manner (Figure $1 C)$; positive cells reached about $40 \%$ of total cells at $24 \mathrm{~h}$ incubation. RGES internalized with slower kinetics, reaching about $30 \%$ of positive cells at $24 \mathrm{~h}$ (i.e., $25 \%$ less than RGDS). RGDS internalization was markedly higher in melanoma cells vs HUVEC (Additional file 2). RGDS internalization was also measured in cytoplasmic extracts of SK-MEL-110 exposed to increasing doses of bt-RGDS for $24 \mathrm{~h}$ at $37^{\circ} \mathrm{C}$ or biotin alone as control (Figure $2 \mathrm{~A}$ ). Internalization was measured by densitometry and was inhibited by an excess of not-biotinylated RGDS, indicating a specific internalization accounting for about $60 \%$ of the total internalization (Figure 2B). Confocal microscopy further supported these results, indicating a mostly cytoplasmic intracellular localization (Figure 2C) at $24 \mathrm{~h}$ treatment.

\section{RGDS-survivin interaction}

The observation that RGDS is able to internalize into melanoma cells raised the question whether RGDS may recognize intracellular targets. Biotinylated-RGDS (btRGDS) was found to directly interact with cytoplasmic extracts and such binding was strongly inhibited by an excess of unlabeled-RGDS (Figure 3A), suggesting that RGDS recognizes specific targets in cytoplasmic lysates.

Survivin is known to be highly expressed in tumors and melanoma playing a key role in survival control $[32,33]$. In SK-MEL-110 melanoma cells it is expressed at levels 


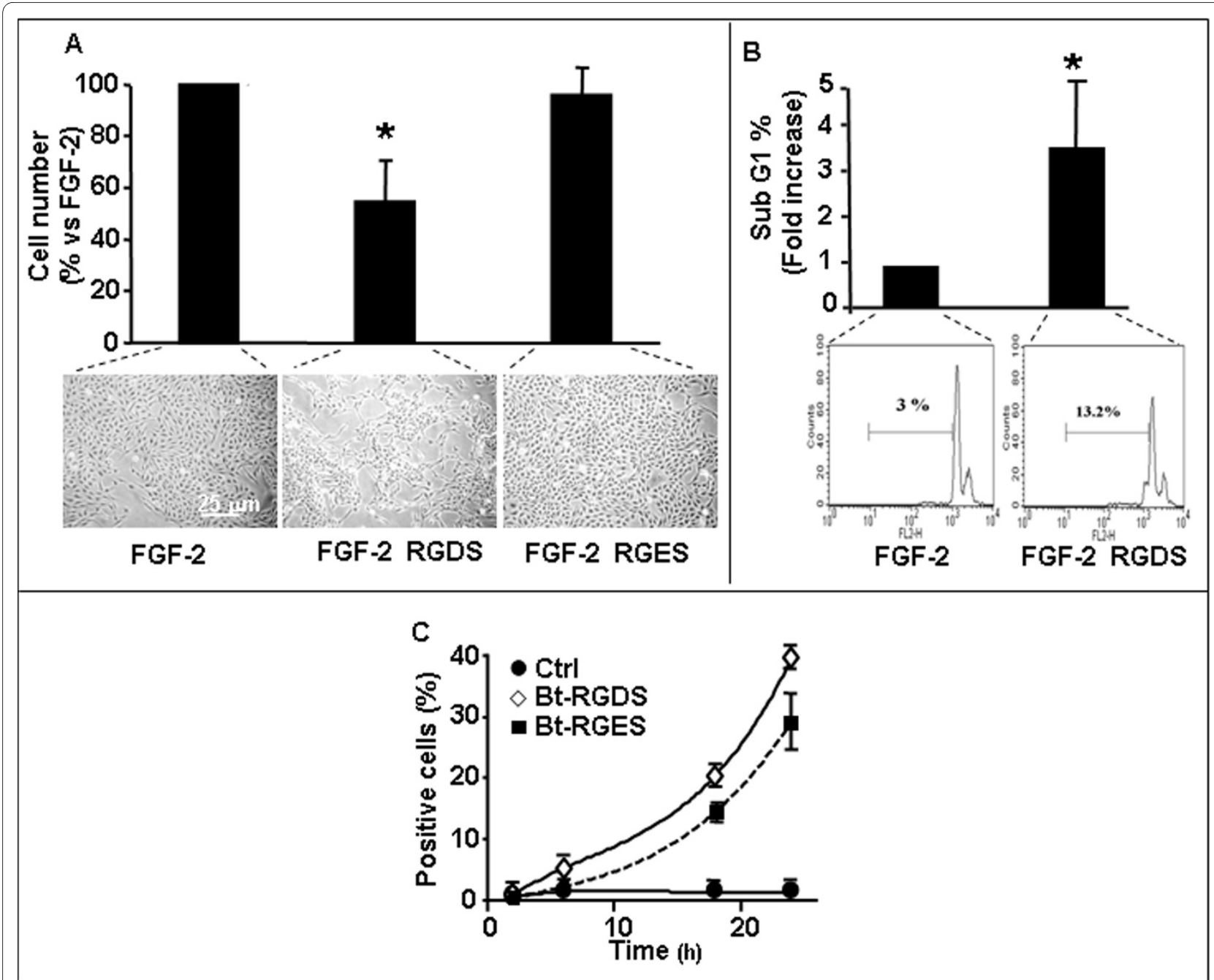

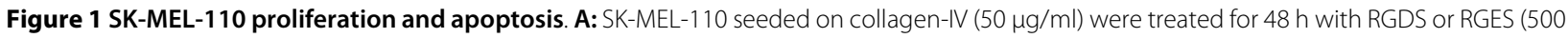
$\mathrm{\mu g} / \mathrm{ml})$ in the presence of FGF-2 $(10 \mathrm{ng} / \mathrm{ml})$. Data are expressed as mean \pm SD of 5 experiments carried out in duplicate. Representative images are reported. B: SK-MEL-1 10 apoptosis was quantified by FACS analysis of PI-stained cells after 48 h RGDS treatment $(500 \mu g / m l)(p<0.05$ vs FGF-2). Three independent experiments were performed and quantified; one representative experiment is shown. C: Biotinylated-RGDS and RGES internalization in SK-MEL-110 was measured by FACS. Cells were treated for different time points $(2,6,16$ and $24 \mathrm{~h}$ ) with bt-RGDS or bt-RGES; internalization was revealed by PE-avidin. Three independent experiments were performed.

higher than endothelial cells (HUVEC) or melanocytes (Additional file 3).

We thus hypothesized a functional interaction between survivin and intracellular RGDS. RGD peptides have been reported by us and by Others to interact with intracellular targets such as pro-caspase- 3 , caspase- 8 and caspase-9 in other cell types $[3,22,23]$. We hypothesized that RGDS may recognize additional intracellular targets, namely survivin. Cytoplasmic lysates of growing SKMEL-110, were incubated with bt-RGDS-coated dynabeads. Proteins interacting with RGDS were then revealed by SDS-page and western blotting and were identified with specific detecting-antibodies, as pro-caspase- 8 , pro-caspase- 9 , pro-caspase- 3 and survivin, while
RGDS did not interact with pro-caspase-1. Pre-incubating lysates with not-biotinylated RGDS abolished interaction of bt-RGDS with survivin, caspase-3, caspase- 8 and caspase-9, indicating a specific binding; such conclusion was further supported by the observation that bt-RGES control peptide is not able to bind with any tested intracellular protein (Figure 3B). Direct binding of RGDS with intracellular proteins was further investigated in overlay assays by direct immobilization of several different proteins onto nitrocellulose membrane. Labeled RGDS was found to directly interact with precursor- and active-caspase-9 and with recombinant survivin and this binding was specifically inhibited, at least in part, in the presence of an excess of unlabeled RGDS. BSA, fibronectin or 


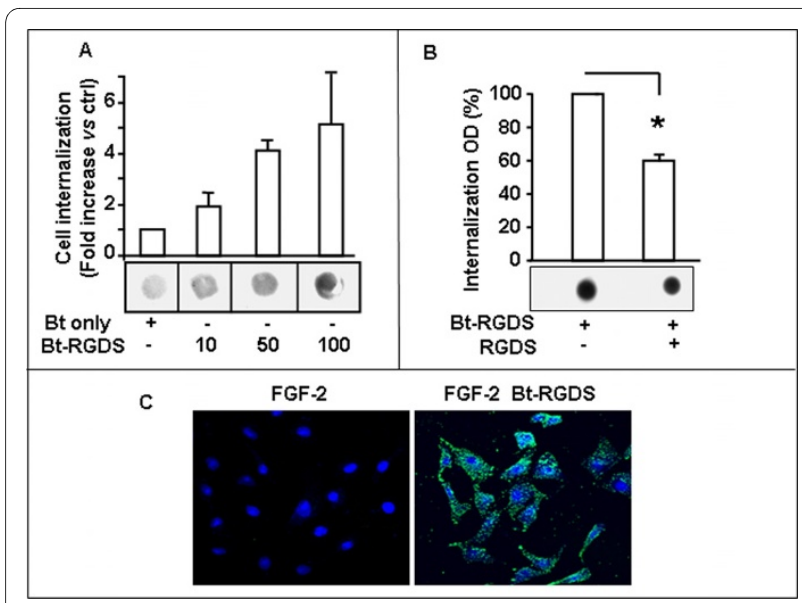

Figure 2 RGDS internalization in melanoma cells. A: Bt-RGDS internalization into live SK-MEL-110 was examined after $24 \mathrm{~h}$ incubation at $37^{\circ} \mathrm{C}$. Cells were treated with biotin alone or with increasing concentrations of bt-RGDS, cytoplasmic extracts were immobilized onto nitrocellulose and biotin presence was detected by avidin-peroxidase kit. Densitometry-quantification of total internalization in three experiments and one representative experiment are reported. B: Total internalization measured in extracts obtained from cells treated with btRGDS $(50 \mu \mathrm{g} / \mathrm{ml})$, and nonspecific internalization in the presence of an excess of unlabeled RGDS (1 mg/ml). Densitometry of three separate experiments and one representative experiment are reported. C: BtRGDS internalization $(500 \mu \mathrm{g} / \mathrm{ml})$ at $24 \mathrm{~h}$ was confirmed by confocal microscopy (original magnification $\times 40$ ). RGDS entered into live melanoma cells (green stain) with a prevalently cytoplasmic localization. Nuclei are shown as blue stain. This experiment was carried out three times in duplicate.

active caspase-1 did not interact with RGDS (Figure 3C). To further investigate such interaction, increasing doses of recombinant survivin $(0.3$ to $5 \mu \mathrm{g})$ were immobilized onto nitrocellulose membrane and incubated with the btRGDS. RGDS bound survivin in a concentration-dependent and saturable manner. Specific binding was computed by subtracting nonspecific binding from the total binding (Figure 4A top and bottom). As a further approach, a solid phase assay was carried out. Recombinant GST (as control), GST-Full length survivin, GST-Nterminus-survivin and GST-C-terminus-survivin were immobilized onto plastic and incubated with increasing concentrations of bt-RGDS in the presence or in the absence of an excess of unlabeled RGDS. Under such conditions RGDS bound Full-length survivin and C-Terminus-survivin in a dose-dependent and saturable way. A $\mathrm{Kd}$ of $27.5 \mu \mathrm{M}$ and $30 \mu \mathrm{M}$, respectively and a Bmax of 0.61 and 0.56 , for the binding to Full-length and C-terminus, respectively (Figure 4B), were computed according to the one-site binding curve-fit equation (1). In contrast, RGDS did not bind the GST-N-terminus fragment (Kd of -161 and Bmax of -0.0079). These data suggested that RGDS-survivin interaction occurs at a single site at the C-Terminus region of survivin.

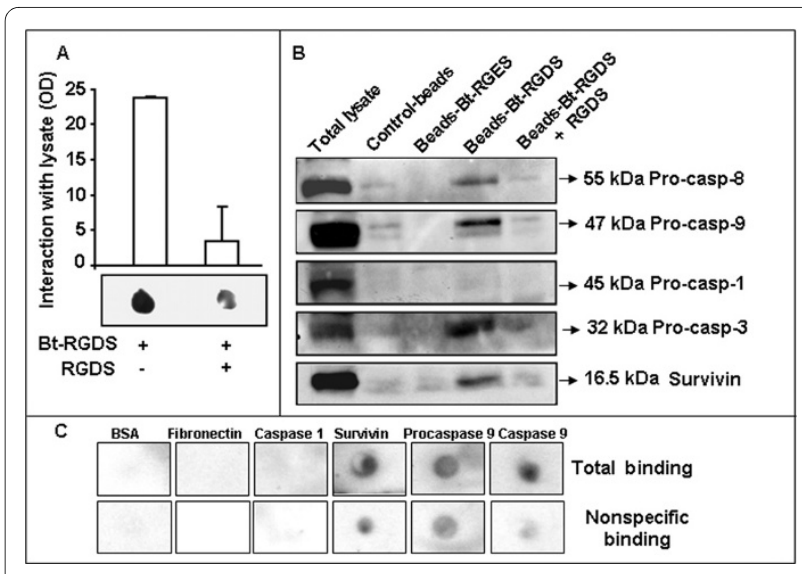

Figure 3 RGDS-survivin interaction. A: Bt-RGDS interaction with cell lysate: cytoplasmic extracts were immobilized onto nitrocellulose and incubated with bt-RGDS. Total binding in the presence of labeled RGDS and nonspecific binding in the presence of an excess of unlabeled RGDS are shown. Densitometry of three different experiments and one representative experiment are reported. B: RGDS interaction with intracellular proteins was assayed by co-precipitation. BSA (control), bt-RGES (specificity control) or bt-RGDS (1 mM) were incubated for $1 \mathrm{~h}$ at $4^{\circ} \mathrm{C}$ with streptavidin-coated dynabeads, then SK-MEL-110 lysate, pre-incubated for $4 \mathrm{~h}$ at $4^{\circ} \mathrm{C}$ with an excess of unlabeled RGDS, was added and incubated overnight at $4^{\circ} \mathrm{C}$. Precipitated proteins were revealed by western blotting using various antibodies (anti pro-caspase-8, anti pro-caspase-9, anti pro-caspase-1, anti pro-caspase-3 and anti-survivin). Total lysate was used as positive control. This experiment was carried out three times. C: Purified recombinant proteins were spotted onto nitrocellulose $(0.9 \mu \mathrm{g} / \mathrm{spot})$. Membrane was incubated for $4 \mathrm{~h}$ at RT with bt-RGDS ( $1 \mathrm{mg} / \mathrm{ml}$ ) (total binding) in the absence or in the presence of an excess of unlabeled RGDS $(10 \mathrm{mg} / \mathrm{ml}$ ) (nonspecific binding). Three independent experiments were performed.

\section{Survivin small interference-RNA}

The reported results demonstrate a specific interaction of RGDS and survivin. We then investigated whether survivin mediates RGDS effects on cell proliferation/survival. To this aim survivin was silenced in SK-MEL-110 and cells were treated with RGDS for $48 \mathrm{~h}$. SiGLO Lamin A/C siRNA was used as positive control of transfection efficiency. Survivin silencing was confirmed by western blotting and showed complete protein down-regulation (Figure 5A top) and induced high mortality in SK-MEL110 (35\%, data not shown), as expected. Under such survivin-deprivation conditions, FGF-2 has a reduced survival effect, as expected, and RGDS completely looses its inhibitory effect (Figure 5A bottom), suggesting that the RGDS anti-proliferative action requires, at least in part, survivin presence. To further confirm such hypothesis, the opposite approach was followed, and survivin-forced expression was achieved by transfection with a specific expression plasmid. Western blotting analysis confirms survivin overexpression as compared to the control (Figure 5B top); under such experimental conditions FGF-2 


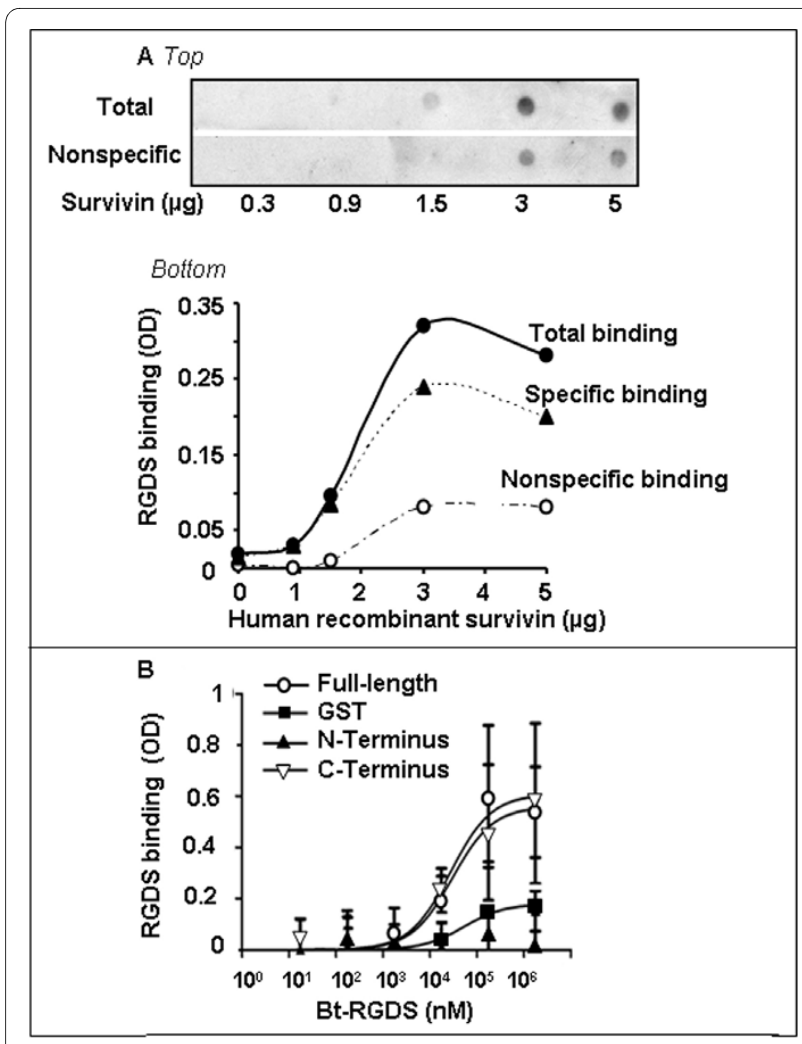

Figure 4 RGDS-survivin binding. A: Increasing doses of purified human-recombinant survivin ( 0.3 to $5 \mu \mathrm{g} / \mathrm{spot}$ ) were immobilized onto membrane and incubated with bt-RGDS in the presence of un-labeled peptide, as competitor (top). A representative experiment of two different assays, is shown. Densitometry quantification is reported (bottom). B: Bt-RGDS binding to recombinant GST-fusion survivin and to N-terminus (Met1-Gly99) or C-terminus (Lys90-Asp142) fragments (175 mM) was evaluated by solid-phase assay (SPA). Proteins were immobilized onto plastic and were incubated with increasing doses of bt-RGDS $(1.75 \mathrm{nM}$ to $1.75 \mathrm{mM})$ in the presence of an excess of un-labeled RGDS. Three independent experiments were performed.

survival effect is increased, as expected, and RGDS maintains its anti-mitogenic effect (Figure 5B bottom).

\section{RGDS effect on caspase-3 expression}

We and Others previously demonstrated that RGDS activates caspase-3 in different cell types [3,22,23], leading to apoptosis. In the present study $48 \mathrm{~h}$ RGDS treatment reduced pro-caspase- 3 (molecular weight $32 \mathrm{kDa}$ ) and increased expression of caspase- 3 active subunit $(17 \mathrm{kDa})$ in SK-MEL-110 (Figure 6A top). Caspase-3 activation was confirmed by confocal microscopy using a specific antibody able to recognize the active form, while RGES control peptide had no effect on caspase-3 activation (Figure $6 \mathrm{~A}$ bottom). Pre-treatment of melanoma cells for $2 \mathrm{~h}$ with Z-VAD-FMK, a general caspases inhibitor, significantly abolished the RGDS anti-proliferative effect (Figure 6B), further indicating that RGDS action was caspase-dependent.

\section{Discussion}

The RGD motif occurs in several ECM proteins and plays a crucial role in integrin-mediated cell adhesion. It has been largely investigated in the past decades as mediator of integrins-dependent cell-adhesion and, consequently, for the effect on survival, invasion, blood coagulation $[21,34,35]$. Recent evidence by different investigators has identified a novel role, namely the RGD ability to act at the intracellular level, to recognize intracellular targets and to activate the apoptotic cascade via a direct caspaseactivation process and caspase cleavage [3,22-24]. Thus a possible role of RGD-containing peptides released from the extracellular matrix and accumulated in the cytosolic compartment has been suggested [36], highlighting the view that extracellular matrix degradation occurring during physiologic and pathologic tissue-remodeling, may generate RGD-containing products acting at the intracellular-level.

We have previously demonstrated that under experimental conditions most-likely abrogating extracellular anti-adhesive effect, RGDS induces apoptosis in HUVEC in integrins-independent way and directly interacts with caspase- 8 and caspase- 9 in HUVEC [3]. RGDS peptide has been studied in several melanoma setting, mostly as an anti-adhesion molecule [37-39], while no data are available on the intracellular effect of RGDS in melanoma cells. Hence we addressed RGDS internalization in these cells and investigated novel intracellular targets involved in the control of melanoma cells survival. Cell adhesion to collagens is RGD-independent [2-4]; thus, in cells seeded onto collagen-IV most of the RGDS biological effects do not depend on its anti-adhesive effects. Under such conditions, RGDS significantly inhibited proliferation of SKMEL-110 in the presence of FGF-2 and induced apoptosis, while the control-peptide RGES was ineffective. RGDS peptide was internalized into live melanoma cells and specifically interacted with the cytoplasmic extract. RGDS-internalization and anti-mitogenic/pro-apoptotic effects were observed in melanoma cells (in the present study) and in HUVEC [3], although kinetics and potency are different due to the different intrinsic features of these two cell types. Interestingly, RGES peptide did not show biological effects but was internalized, although with slower kinetics compared to RGDS. This observation agrees with previous data collected on other RGDS controls [23] and opens the question regarding mechanisms of internalization and its specificity. Further investigations are needed to discriminate between passive diffusion of small molecules such as RGES and RGDS, and specific-RGDS-internalization [40]. RGDS directly and specifically bound pro-caspase- 8 , pro-caspase- 9 and procaspase-3, while it did not bind pro-caspase-1, a proinflammatory caspase not directly involved in the apoptosis cascade. Such data may support the hypothesis that 


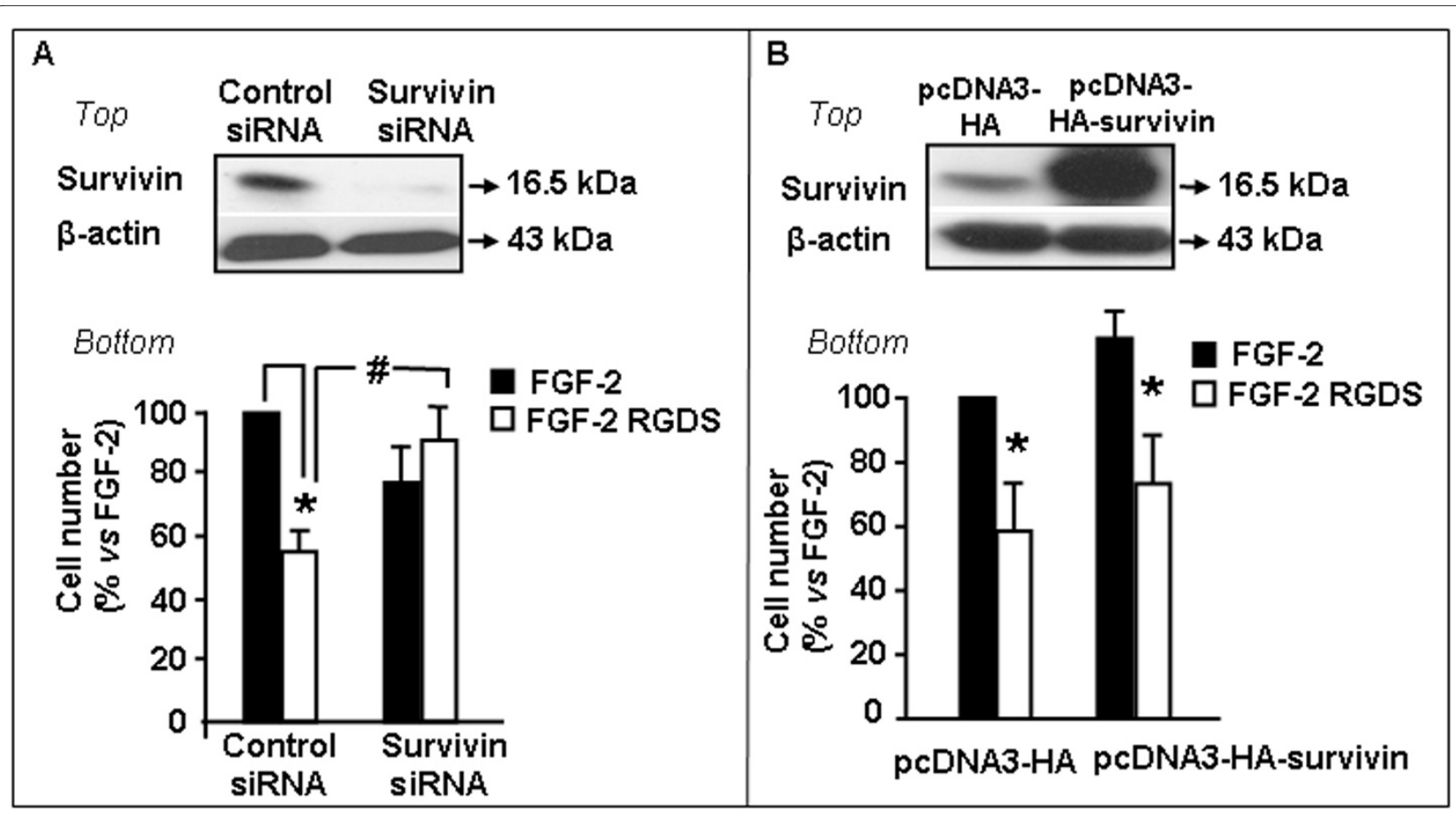

Figure 5 RGDS effect require survivin expression. SK-MEL-110 were transfected with human survivin siRNA or with control siRNA before RGDS treatment. SiGLO Lamin A/C siRNA was used as control of transfection efficiency. A Top: Survivin silencing was confirmed by western blotting after 72 h transfection. Bottom: FGF-2 (10 ng/ml)-induced proliferation in survivin-silenced or in control, after RGDS treatment for $48 \mathrm{~h}$ ( ${ }^{*} \mathrm{p}<0.05 \mathrm{vs}$ FGF-2 and \# $\mathrm{p}<0.005$ vs FGF-2 in silenced cells). Three independent experiments were performed in duplicate. B Top: Full length HA-tagged survivin was overexpressed in melanoma cells before RGDS treatment. Over-expression was confirmed by western blotting after $24 \mathrm{~h}$ transfection. Bottom: RGDS effect on FGF-2-induced proliferation in transfected-SK-MEL-110 after $48 \mathrm{~h}$ treatment ( $<0.01$ vs FGF-2). Three independent experiments were performed in duplicate.

intracellular targets of RGDS may comprise different molecules of the apoptotic cascade. Conversely, RGES did not interact with any tested intracellular target. Survivin was found to be a novel RGDS intracellular direct target and a specific RGDS-binding site was found at survivin C-terminus, where an extended alpha-helical coiled-coil portion is located. Such domain is known to play a key role for the survivin interaction with microtubules and cell division-control. Additional studies will be carried out to identify the specific amino acids involved in RGDS-survivin interaction. Survivin controls cell division, apoptosis and cellular stress response and protects cells against both caspase-dependent and caspase-independent cell death $[41,42]$. Its interaction with RGDS although un-expected, was not surprising, given the previous evidence showing direct interaction of RGDS with other key players of the survival/apoptosis machine $[3,22,23]$. Survivin-silencing achieved with a specific siRNA suppressed the anti-mitogenic action of RGDS, while the anti-proliferative effect of RGDS was maintained when survivin expression was up-regulated with a specific expression plasmid, indicating that survivin is required for RGDS anti-mitogenic effect in SK-MEL-110 and that cell-sensitivity to RGDS actions may depend at least in part on survivin levels in different physiological and pathological conditions. Such consideration supports survivin as a potential target for anti-tumor approaches. Indeed, several studies demonstrated that anticancer drugs as colecoxib, COX-2 inhibitors or silibilin derivates down-regulate survivin expression in a wide range of tumor cells, inducing apoptosis $[43,44]$.

\section{Conclusions}

The present study indicates that in melanoma cells RGDS peptide interacts with intracellular targets, namely apoptotic caspases and survivin; identifies RGDS as a survivintargeting molecule and indicates a novel mechanism to control cell proliferation.

\section{Methods}

\section{Cells culture}

Human metastatic melanoma cells line SK-MEL-110 [45] were grown in DMEM (Hyclone, Logan, UT) supplemented with $2 \mathrm{mM}$ L-glutamine, $100 \mathrm{IU} / \mathrm{ml}$ penicillinstreptomycin (Gibco, Invitrogen corporation, Carlsbad, $\mathrm{CA}$ ), and 10\% heat-inactivated FCS (Hyclone, Logan, $\mathrm{UT})$. Cells were cultured at $37^{\circ} \mathrm{C}$ in a $5 \% \mathrm{CO}_{2}$ atmosphere. 


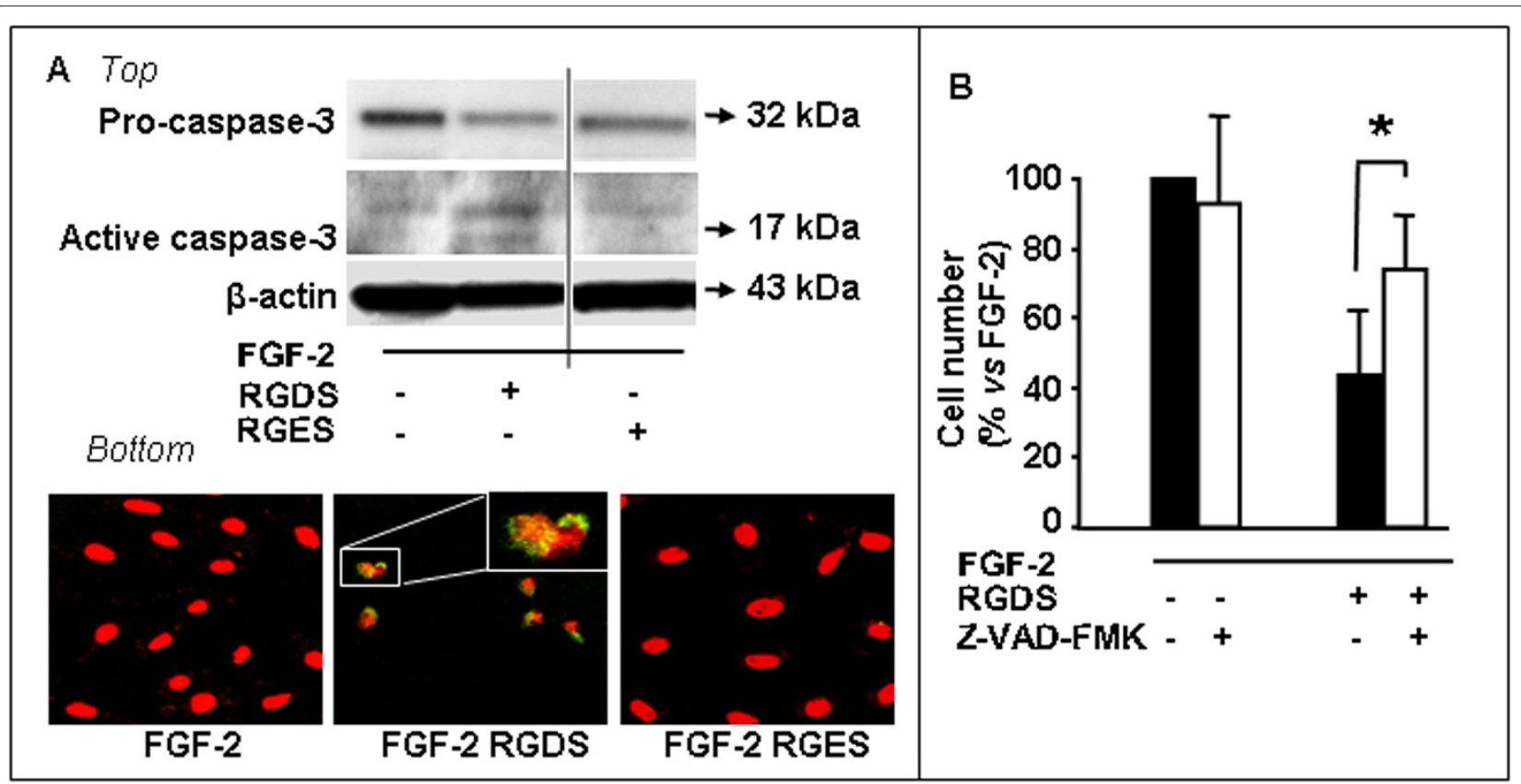

Figure 6 RGDS treatment activates caspase-3. A: SK-MEL-110 seeded on collagen-IV were incubated for $48 \mathrm{~h}$ with FGF-2 in the presence or in the absence of RGDS or RGES (500 $\mu \mathrm{g} / \mathrm{ml})$. Top: Pro-caspase 3 cleavage and caspase-3 activation were observed by western blotting. Bottom: caspase-3 activation was confirmed by confocal microscopy using an anti-active caspase-3 antibody. B: Pre-treatment ( 2 h) of melanoma cells with Z-VAD-FMK $(50 \mu \mathrm{M})$, a general caspases inhibitor, abolished the RGDS anti-proliferative effect ( $p<0.005$ vs FGF-2 in the presence of Z-VAD-FMK). All these experiments were carried out three times in duplicate.

\section{Proliferation assay and apoptosis}

SK-MEL-110 were plated in 6 -well plates $\left(8 \times 10^{4}\right.$ cells/ well) on collagen-IV $(50 \mu \mathrm{g} / \mathrm{ml})$ and were grown for $24 \mathrm{~h}$ in complete medium in $5 \% \mathrm{CO}_{2}$. Cells were then serumstarved for $24 \mathrm{~h}$ and subsequently treated with RGDS (Bachem, Bubendorf, Switzerland) or RGES as control (Sigma-Aldrich, St Louis, MO) $(500 \mu \mathrm{g} / \mathrm{ml})$ dissolved in DMEM containing FGF-2 (Pierce-Endogen, Rockford, IL) for $48 \mathrm{~h}$. Then, cells were photographed, harvested by trypsin-EDTA and counted using hemacytometer. In other experiments, cells were pre-treated with a general caspase inhibitor (Z-VAD-FMK) $(50 \mu \mathrm{M})$ (R\&D Systems, Minneapolis, MN) for $2 \mathrm{~h}$ before RGDS treatment. To analyze cell cycle and sub-G1-phase, cells were fixed in ice-cold $70 \%$ ethanol and stained with propidium iodide (PI) at $10 \mu \mathrm{g} / \mathrm{ml}$ final concentration. Flow cytometry was performed on a Profile I flow cytometer (FACSCalibur, BD-Biosciences).

\section{Biotinylated-RGDS (bt-RGDS) internalization and interaction with recombinant proteins}

To investigate peptides internalization, cells were treated with the biotinylated-RGDS (bt-RGDS) or biotinylatedRGES (bt-RGES) (NeoMPS-SA, Strasbourg, France) as control for different time-points, stained with phycoerythrin conjugated-avidin and analyzed by FACS. In additional experiments cells grown on collagen-IV were serum-starved for $48 \mathrm{~h}$ and treated for $24 \mathrm{~h}$ with biotin alone or with different doses of bt-RGDS (10-50-100 $\mu \mathrm{g}$ / $\mathrm{ml})$. In other experiments cells were treated with $50 \mu \mathrm{g} /$ $\mathrm{ml}$ bt-RGDS with an excess of $1 \mathrm{mg} / \mathrm{ml}$ un-labeled RGDS as specific competitor. Cells were washed to eliminate btRGDS bound to the membranes and a cytoplasmic extract was prepared as previously reported [3]. Cytoplasmic lysates were spotted onto nitrocellulose, blocked with 5\% milk in TPBS (0.1\% Tween 20 in PBS) and incubated for $1 \mathrm{~h}$ at RT with a Vectastain ABC-peroxidase kit (Vector) followed by chemiluminescence reaction and exposure to Kodak film (Eastman Kodak). Interaction was quantified by densitometry (GS 710; Bio-Rad) and analyzed using the "Quantity one" software (Bio-Rad).

In other experiments $40 \mu \mathrm{g}$ of growing cells cytoplasmic extract, or increasing doses of recombinant human survivin (0.3-0.9-1.5-3-5 $\mu \mathrm{g}$ ) (CP-Biotech, Sylvania, $\mathrm{OH}$ ) or other recombinant proteins, as caspases-1 and -9, procaspase-9 (Alexis), fibronectin $(0.9 \mu \mathrm{g})$ (Becton-Dickinson, Bradford, MA) and BSA were spotted onto nitrocellulose, incubated for $4 \mathrm{~h}$ at RT with bt-RGDS $(1 \mathrm{mg} / \mathrm{ml})$ in the presence or absence of RGDS-excess $(10 \mathrm{mg} / \mathrm{ml})$ to measure the specific binding.

\section{Confocal microscopy}

SK-MEL-110 seeded on coverslips coated with collagenIV and treated for $24 \mathrm{~h}$ with bt-RGDS $(500 \mu \mathrm{g} / \mathrm{ml})$, were washed as previously reported to eliminate the peptide bound to the membranes [3]. Cells were fixed with $3 \%$ 
paraformaldehyde in PBS, pH 7.4, for 10 minutes, permeabilized with $0.1 \%$ Triton X-100 in PBS, pH 7.4, for 5 minutes at RT, and blocked for 30 minutes with BSA $2 \%$ in PBS, pH 7.4, at RT, followed by incubation with fluorescein avidin (1:40; Vector-Laboratories, Peterborough, UK) in PBS, pH 7.4, for $1 \mathrm{~h}$ at RT. After washing in $0.3 \%$ Triton X-100 in PBS, cells were incubated with PI at a final concentration of $5 \mu \mathrm{g} / \mathrm{ml}$ to visualize nuclei and analyzed using a Zeiss LSM 510 meta-confocal microscope (Zeiss). Laser power, beam splitters, filter settings, pinhole diameters and scan-mode were the same for all examined samples. To visualize active caspase- 3 form, cells were treated with RGDS or RGES, fixed and incubated with a rabbit-monoclonal anti-active caspase-3 (1:150) (Abcam Inc,. Cambridge, MA).

\section{Western blotting}

SK-MEL-110 treated as described in the proliferation assay paragraph, were lysed with RIPA buffer. Samples were boiled, loaded and separated by sodium dodecyl sulfate-polyacrylamide gel electrophoresis (SDS-PAGE) and transferred to nitrocellulose membrane. Membrane was blocked with 5\% milk (Bio-Rad Laboratories) in TPBS (0.1\% Tween 20 in PBS, pH 7.4), washed and incubated with mouse anti-survivin (1:200) (Santa Cruz Biotechnology, Santa Cruz, CA), rabbit anti-caspase 3 (1:200) (Santa Cruz Biotechnology, Alexa, CA,), or mouse anti- $\beta$-actin (1:5000) (Sigma-Aldrich, St Louis, MO) in milk 5\% TPBS $0.1 \%$ for $1 \mathrm{~h}$ at RT. Horseradish peroxidase-conjugated secondary antibodies (Pierce) were used, followed by chemiluminescence (ECL; Amersham, Buckinghamshire, United Kingdom) and autoradiography.

\section{Precipitation with streptavidin-coated Dynabeads}

Streptavidin-coated Dynabeads (M-270, $2.8 \mu \mathrm{m}$, Dynal) were re-suspended, washed in PBS three times, using a magnetic holder, re-suspended and $1 \times 10^{3}$ pmoles of btRGDS, BSA or bt-RGES per mg beads were added, incubated for $1 \mathrm{~h}$ at $4^{\circ} \mathrm{C}$ and washed in PBS for five times. Growing SK-MEL-110 were lysed as reported [22], preincubated with $10 \mu \mathrm{l}$ RGDS as specific competitor (1 $\mathrm{mM}$ ) and incubated with activated beads, at $4^{\circ} \mathrm{C}$ overnight with unidirectional mixing. Samples were boiled and separated by SDS-PAGE as described above and incubated with antibody to survivin (1:200), caspase-3 (1:200), caspase-8 (1:200) (Santa Cruz Biotechnology, Alexa, CA), caspase-9 (1:1000) (Pharmingen, San Diego, CA), caspase-1 (1:500) (Alexis, San Diego, CA). Detection was performed as described above.

\section{Survivin cloning and expression}

Full length HA-tagged Survivin cDNA (GeneBank NM_001168) was generated by PCR using total cDNA from HeLa cells as template.
The primers used were:

GATCAAGCTTATGTATCCGTATGATGTTCCTGATTATGCTGGTGCCCCGACGTTGCC (forward) and GATCGGATCCGGAAGTGGTGCAGCCACTC (reverse) (Invitrogen).

Restriction sites (underlined) for the endonucleases HindIII and BamHI were used for cloning in pcDNA3 vector (Invitrogen). All constructs made by PCR were sequence-verified. Recombinant HA-survivin was expressed in SK-MEL-110 by transient transfection using Lipofectamine Plus Reagent (Invitrogen) according to the manufacturer's instruction. pcDNA-HA empty vector was used as control. Transfection efficiency was evaluated using a pEGFP-N1 reporter vector at a HA-survivin plasmid molar ratio of 4:1. FGF-2-induced proliferation in transfected cells was evaluated after RGDS $48 \mathrm{~h}$ treatment. Protein expression was detected by western blotting.

Full length survivin and both N-terminus (Met1-Gly99) or C-terminus (Lys90-Asp142) were PCR amplified and cloned, using EcoRI and BamHI restriction sites, in pGex6P2 (GE Healthcare) for expression of GST fusion proteins in E. coli BL21(DE3)pLysS (PROMEGA, Southampton, United Kingdom).

The primers used were:

GATGGATCCATGGGTGCCCCGACGTTGC (Met1 forward),

\section{GATGAATTCTCAATCCATGGCAGCCAGCTG}

(Asp142 reverse),

\section{GATGA $\boldsymbol{A} \boldsymbol{T} \boldsymbol{T C}$ TCAACCAAGGGTTAATTCT-}

TCAAAC (Gly99 reverse) and

GATGGATCCAAGAAGCAGTTTGAAGAATTAAC

(Lys90 forward).

GST-fusion proteins were verified by SDS-PAGE and Coomassie staining and their concentration was determined by Bradford protein-assay.

\section{Solid Phase Assay}

Bt-RGDS binding to recombinant GST-fusion proteins was evaluated by solid-phase assay (SPA) as previously described [46] with modifications. Briefly, microtiter plates (Costar, Cambridge, MA) were coated with $175 \mathrm{nM}$ $(100 \mu \mathrm{l} /$ well) recombinant GST-fusion proteins diluted in AC7.5 buffer for $4 \mathrm{~h}$ at RT. Wells were blocked in $30 \mathrm{mg} /$ $\mathrm{ml} \mathrm{BSA}(300 \mu \mathrm{L} /$ well $)$ overnight at $4^{\circ} \mathrm{C}$, washed and incubated for $4 \mathrm{~h}$ at RT with increasing doses of bt-RGDS (from 1.75 to $1.75 \mathrm{mM}$ ), in the presence or in the absence of an excess of not-biotinylated RGDS, as specific competitor. After washing four times and incubation for $1 \mathrm{~h}$ at RT with $100 \mu \mathrm{l} /$ well Vectastain-ABC Reagent (Vector Laboratories, Burlingame, CA), wells were stained with the ELISA Amplification System (Invitrogen, Carlsbad, CA) according to manufacturer's instructions and absorption at $495 \mathrm{~nm}\left(A_{495}\right)$ was determined. Specific 
binding was computed by subtracting nonspecific from total binding at each concentration. Curve fit was carried out according to the following one-site specific bind equation (GraphPad Prism-4 software):

$$
\mathrm{Y}=\mathrm{B} \max ^{*} \mathrm{X} /(\mathrm{Kd}+\mathrm{X})
$$

where $\mathrm{X}$ is ligand concentration, $\mathrm{Y}$ is the specific binding, Bmax is the maximum specific binding in the same units as $\mathrm{Y}, \mathrm{Kd}$ is the equilibrium binding constant, in the same units as $\mathrm{X}$.

\section{siRNA interference assays}

SK-MEL-110 were seeded in 6-well-plates on collagen-IV $\left(1 \times 10^{5}\right.$ per well). Twenty-four hours later cells were transfected with human survivin siRNA (100 nM) or control siRNA-A (Santa Cruz Biotechnology) using Lipofectamine Plus Reagent according to manufacturer's instructions. SiGLO Lamin A/C siRNA (DharmaconRNAi Technologies) was used as control of transfection efficiency. After $72 \mathrm{~h}$ silencing, cells were treated for $48 \mathrm{~h}$ with FGF-2 $(10 \mathrm{ng} / \mathrm{ml})$ in the presence or in the absence of RGDS $(500 \mu \mathrm{g} / \mathrm{ml})$. Cells were counted using hemacytometer. Silencing of survivin protein was confirmed by western blotting.

\section{Statistics}

Data were expressed as mean \pm S.D. Student's two-tailed $t$ test was performed and $\mathrm{p} \leq 0.05$ was considered statistically significant.

\section{Additional material}

\section{Additional file 1 RGDS effect on cell cycle in SK-MEL-110. Cells were} treated with FGF-2 $(10 \mathrm{ng} / \mathrm{ml})$ in the presence or in the absence of RGDS $(500 \mathrm{\mu g} / \mathrm{ml})$. RGDS treatment interferes with cell cycle. A representative histogram of three independent experiments was reported.

Additional file 2 RGDS internalization in HUVEC cells and SK-MEL110. RGDS internalization in HUVEC and SK-MEL-110 was measured by FACS. Cells were treated for 6 and $24 \mathrm{~h}$ with biotinylated-RGDS; internalization was revealed by PE-avidin and measured by FACS analysis. Three independent experiments were carried out.

Additional file 3 Survivin expression in HUVEC, melanocytes and SKMEL-110. Human epidermal melanocytes NHEM-neo (Lonza) were grown in MBM-2 supplemented with MGM-4 SingleQuots ( $\mathrm{CaCl} 2$, FGF-2, PMA, rhInsulin, Hydrocortisone, BPE, FBS and Gentamicin/Amphotericin-B) (Lonza). Human umbilical vein endothelial cells (HUVECs; Lonza) were maintained in EBM-2 medium (Lonza) supplemented with endothelial growth medium 2 (EGM-2) kit (FCS, hydrocortisone, hFGF-B, VEGF, R3-IGF-1, ascorbic acid, hEGF, GA-1000, heparin), according to manufacturer's instructions. Cells were cultured at $37^{\circ} \mathrm{C}$ in a $5 \% \mathrm{CO}_{2}$ atmosphere. Survivin expression in three different cell types (HUVEC, NHEM-Neo or SK-MEL-110) was examined by western blotting. $\beta$-actin was used as control of equal loading. One representative experiment was reported, while the quantification refers to 3 different experiments.

\section{Abbreviations}

ECM: extracellular matrix; RGDS: Arg-Gly-Asp-Ser; RGES: Arg-Gly-Glu-Ser; RT: room temperature; FCS: Fetal calf serum; BSA: bovine serum albumin; HA: haemoagglutinin; siRNA: small interference RNA; FGF-2: human Fibroblast Growth Factor-2; bt-RGDS: biotinylated-RGDS; bt-RGES: biotinylated-RGES.

\section{Competing interests}

The authors declare that they have no competing interests.

\section{Authors' contributions}

MS Aguzzi: performed experiments, participated in data interpretation and manuscript writing; P. Fortugno: performed plasmid construction and purification, recombinant protein preparation and data interpretation; C. Giampietri: performed internalization experiments; G. Ragone performed internalization experiments; M.C. Capogrossi: participated in study coordination and data interpretation; A. Facchiano performed study supervision, data discussion and manuscript writing. All authors read and approved the final manuscript.

\section{Acknowledgements}

We kindly thank Italia-USA Bioinformatics/Proteomics Facility at CNR (Avellino) and Facility for Complex Protein Mixture Analysis at the Dipartimento di Ematologia, Oncologia e Medicina Molecolare, ISS (Rome), Italy.

The present study was supported in part by the project funded by Italian Ministry of Health (RF07 onc-25/3 and RFPS-2006-7-342220) and by Progetto Oncoproteomica Italia-USA (n. 527B/2A/5).

\section{Author Details}

'Laboratorio Patologia Vascolare, Istituto Dermopatico dell'Immacolata, IDIIRCCS, Roma, Italy, 2Laboratorio Biologia Molecolare e Cellulare, Istituto Dermopatico dell'Immacolata, IDI-IRCCS, Roma, Italy, ${ }^{3}$ Dipartimento di Istologia e Embriologia Medica, Università di Roma "Sapienza", Roma, Italy and "Laboratorio Oncogenesi Molecolare, Istituto Dermopatico dell'Immacolata, IDI-IRCCS, Roma, Italy

Received: 15 January 2010 Accepted: 22 April 2010

Published: 22 April 2010

\section{References}

1. Hynes RO: Integrins: bidirectional, allosteric signaling machines. Cell 2002, 110:673-687.

2. Rosenow F, Ossig R, Thormeyer D, Gasmann P, Schluter K, Brunner G, Haier J, Eble JA: Integrins as antimetastatic targets of RGD-independent snake venom components in liver metastasis [corrected]. Neoplasia 2008, 10:168-176.

3. Aguzzi MS, Giampietri C, De Marchis F, Padula F, Gaeta R, Ragone G, Capogrossi MC, Facchiano A: RGDS peptide induces caspase 8 and caspase 9 activation in human endothelial cells. Blood 2004, 103:4180-4187.

4. Eble JA, Haier J: Integrins in cancer treatment. Curr Cancer Drug Targets 2006, 6:89-105.

5. Brakebusch C, Bouvard D, Stanchi F, Sakai T, Fassler R: Integrins in invasive growth. J Clin Invest 2002, 109:999-1006

6. Carreras Puigvert J, Huveneers S, Fredriksson L, Op Het Veld M, Water B van de, Danen EH: Cross-talk between integrins and oncogenes modulates chemosensitivity. Mol Pharmacol 2009, 75:947-955.

7. Somanath PR, Ciocea A, Byzova TV: Integrin and growth factor receptor alliance in angiogenesis. Cell Biochem Biophys 2009, 53:53-64.

8. Miller MW, Basra S, Kulp DW, Billings PC, Choi S, Beavers MP, McCarty OJ, Zou Z, Kahn ML, Bennett JS, DeGrado WF: Small-molecule inhibitors of integrin alpha2beta1 that prevent pathological thrombus formation via an allosteric mechanism. Proc Natl Acad Sci USA 2009, 106:719-724.

9. Zhao H, Patrick Ross F: Mechanisms of osteoclastic secretion. Ann N Y Acad Sci 2007, 1116:238-244.

10. White DE, Muller WJ: Multifaceted roles of integrins in breast cancer metastasis. J Mammary Gland Biol Neoplasia 2007, 12:135-142.

11. Kuphal $S$, Bauer R, Bosserhoff AK: Integrin signaling in malignant melanoma. Cancer Metastasis Rev 2005, 24:195-222.

12. Sheu JR, Wu CH, Chen YC, Hsiao G, Lin CH: Mechanisms in the inhibition of neointimal hyperplasia with triflavin in a rat model of balloon angioplasty. J Lab Clin Med 2001, 137:270-278.

13. Marsh N, Williams V: Practical applications of snake venom toxins in haemostasis. Toxicon 2005, 45:1171-1181.

14. Cao L, Du P, Jiang SH, Jin GH, Huang QL, Hua ZC: Enhancement of antitumor properties of TRAIL by targeted delivery to the tumor neovasculature. Mol Cancer Ther 2008, 7:851-861.

15. Tan TW, Yang WH, Lin YT, Hsu SF, Li TM, Kao ST, Chen WC, Fong YC, Tang $\mathrm{CH}$ : Cyr61 increases migration and MMP-13 expression via alphavbeta3 
integrin, FAK, ERK and AP-1-dependent pathway in human chondrosarcoma cells. Carcinogenesis 2009, 30:258-268.

16. Hofland LJ, Capello A, Krenning EP, de Jong M, van Hagen MP: Induction of apoptosis with hybrids of Arg-Gly-Asp molecules and peptides and antimitotic effects of hybrids of cytostatic drugs and peptides. J NuCl Med 2005, 46:191S-198S.

17. Capello A, Krenning EP, Bernard BF, Breeman WA, van Hagen MP, de Jong M: Increased cell death after therapy with an Arg-Gly-Asp-linked somatostatin analog. J Nucl Med 2004, 45:1716-1720.

18. Ellerby HM, Arap W, Ellerby LM, Kain R, Andrusiak R, Rio GD, Krajewski S, Lombardo CR, Rao R, Ruoslahti E, et al:: Anti-cancer activity of targeted pro-apoptotic peptides. Nat Med 1999, 5:1032-1038.

19. Borgne-Sanchez A, Dupont S, Langonne A, Baux L, Lecoeur H, Chauvier D, Lassalle M, Deas O, Briere JJ, Brabant M, et al: Targeted Vpr-derived peptides reach mitochondria to induce apoptosis of alphaVbeta3expressing endothelial cells. Cell Death Differ 2007, 14:422-435.

20. Liu Z, Niu G, Shi J, Liu S, Wang F, Chen X: (68)Ga-labeled cyclic RGD dimers with Gly(3) and PEG (4) linkers: promising agents for tumor integrin alpha (v)beta (3) PET imaging. Eur J Nucl Med Mol Imaging 2009, 36:947-957.

21. Giancotti FG, Ruoslahti E: Integrin signaling. Science 1999, 285:1028-1032.

22. Buckley CD, Pilling D, Henriquez NV, Parsonage G, Threlfall K, ScheelToellner D, Simmons DL, Akbar AN, Lord JM, Salmon M: RGD peptides induce apoptosis by direct caspase-3 activation. Nature 1999, 397:534-539.

23. Adderley SR, Fitzgerald DJ: Glycoprotein Ilb/llla antagonists induce apoptosis in rat cardiomyocytes by caspase-3 activation. $\mathrm{J} \mathrm{Biol} \mathrm{Chem}$ 2000, 275:5760-5766.

24. Matsuki K, Sasho T, Nakagawa K, Tahara M, Sugioka K, Ochiai N, Ogino S, Wada Y, Moriya H: RGD peptide-induced cell death of chondrocytes and synovial cells. J Orthop Sci 2008, 13:524-532.

25. Zaffaroni N, Pennati M, Daidone MG: Survivin as a target for new anticancer interventions. J Cell Mol Med 2005, 9:360-372.

26. Grossman D, Altieri DC: Drug resistance in melanoma: mechanisms, apoptosis, and new potential therapeutic targets. Cancer Metastasis Rev 2001, 20:3-11.

27. Mita AC, Mita MM, Nawrocki ST, Giles FJ: Survivin: key regulator of mitosis and apoptosis and novel target for cancer therapeutics. Clin Cancer Res 2008, 14:5000-5005.

28. Du ZX, Zhang HY, Gao surda X, Wang HQ, Li YJ, Liu GL: Antisurvivin oligonucleotides inhibit growth and induce apoptosis in human medullary thyroid carcinoma cells. Exp Mo/ Med 2006, 38:230-240.

29. Gu CM, Zhu YK, Ma YH, Zhang M, Liao B, Wu HY, Lin HL: Knockdown of survivin gene by vector-based short hairpin RNA technique induces apoptosis and growth inhibition in Burkitt's lymphoma Raji cell line. Neoplasma 2006, 53:206-212.

30. Zhang R, Wang T, Li KN, Qin WW, Chen R, Wang K, Jia LT, Zhao J, Wen WH, Meng $Y L$, et al: A survivin double point mutant has potent inhibitory effect on the growth of hepatocellular cancer cells. Cancer Biol Ther 2008, 7:547-554

31. Pennati $M$, Folini $M$, Zaffaroni $N$ : Targeting survivin in cancer therapy. Expert Opin Ther Targets 2008, 12:463-476.

32. Grossman D, Kim PJ, Schechner JS, Altieri DC: Inhibition of melanoma tumor growth in vivo by survivin targeting. Proc Natl Acad Sci USA 2001, 98:635-640

33. Andersen MH, Svane IM, Becker JC, Straten PT: The universal character of the tumor-associated antigen survivin. Clin Cancer Res 2007, 13:5991-5994

34. Maubant S, Saint-Dizier D, Boutillon M, Perron-Sierra F, Casara PJ, Hickman JA, Tucker GC, Van Obberghen-Schilling E: Blockade of alpha v beta3 and alpha $v$ beta 5 integrins by RGD mimetics induces anoikis and not integrin-mediated death in human endothelial cells. Blood 2006, 108:3035-3044

35. Plow EF, Cierniewski CS, Xiao Z, Haas TA, Byzova TV: Alphallbbeta3 and its antagonism at the new millennium. Thromb Haemost 2001, 86:34-40.

36. Perlot RL Jr, Shapiro IM, Mansfield K, Adams CS: Matrix regulation of skeletal cell apoptosis II: role of Arg-Gly-Asp-containing peptides. $J$ Bone Miner Res 2002, 17:66-76.

37. Oliva IB, Coelho RM, Barcellos GG, Saldanha-Gama R, Wermelinger LS, Marcinkiewicz C, Benedeta Zingali R, Barja-Fidalgo C: Effect of RGD- disintegrins on melanoma cell growth and metastasis: involvement of the actin cytoskeleton, FAK and c-Fos. Toxicon 2007, 50:1053-1063.

38. Ebrahimnejad A, Streichert T, Nollau P, Horst AK, Wagener C, Bamberger AM, Brummer J: CEACAM1 enhances invasion and migration of melanocytic and melanoma cells. Am J Pathol 2004, 165:1781-1787.

39. Chung KH, Kim SH, Han KY, Sohn YD, Chang SI, Baek KH, Jang Y, Kim DS, Kang IC: Inhibitory effect of salmosin, a Korean snake venom-derived disintegrin, on the integrin alphav-mediated proliferation of SK-Mel-2 human melanoma cells. J Pharm Pharmacol 2003, 55:1577-1582.

40. Castel S, Pagan R, Mitjans F, Piulats J, Goodman S, Jonczyk A, Huber F, Vilaro S, Reina M: RGD peptides and monoclonal antibodies, antagonists of alpha(v)-integrin, enter the cells by independent endocytic pathways. Lab Invest 2001, 81:1615-1626.

41. Altieri DC: The case for survivin as a regulator of microtubule dynamics and cell-death decisions. Curr Opin Cell Biol 2006, 18:609-615.

42. Liu T, Brouha B, Grossman D: Rapid induction of mitochondrial events and caspase-independent apoptosis in Survivin-targeted melanoma cells. Oncogene 2004, 23:39-48.

43. Deep G, Oberlies NH, Kroll DJ, Agarwal R: Isosilybin B and isosilybin A inhibit growth, induce $\mathrm{G} 1$ arrest and cause apoptosis in human prostate cancer LNCaP and 22Rv1 cells. Carcinogenesis 2007, 28:1533-1542

44. Yamamoto H, Ngan CY, Monden M: Cancer cells survive with survivin. Cancer Sci 2008, 99:1709-1714

45. Faraone D, Aguzzi MS, Toietta G, Facchiano AM, Facchiano F, Magenta A, Martelli F, Truffa S, Cesareo E, Ribatti D, et al:: Platelet-derived growth factor-receptor alpha strongly inhibits melanoma growth in vitro and in vivo. Neoplasia 2009, 11:732-742.

46. Faraone D, Aguzzi MS, Ragone G, Russo K, Capogrossi MC, Facchiano A: Heterodimerization of FGF-receptor 1 and PDGF-receptor-alpha: a novel mechanism underlying the inhibitory effect of PDGF-BB on FGF2 in human cells. Blood 2006, 107:1896-1902.

doi: $10.1186 / 1476-4598-9-84$

Cite this article as: Aguzzi et al., Intracellular targets of RGDS peptide in melanoma cells Molecular Cancer 2010, 9:84

\section{Submit your next manuscript to BioMed Centra and take full advantage of:}

- Convenient online submission

- Thorough peer review

- No space constraints or color figure charges

- Immediate publication on acceptance

- Inclusion in PubMed, CAS, Scopus and Google Scholar

- Research which is freely available for redistribution 